\title{
Potensi Dark Tourism Pasca Bencana di Kawasan Ekonomi Khusus Tanjung Lesung, Provinsi Banten
}

\author{
Er. Ummi Kalsum*1, Faisal2, Djauhar Arifin³, Bambang Sapto Utomo4, Daeng Noerdjmal5 \\ Sekolah Tinggi Pariwisata Bandung1,2,3,4,5 \\ Email: ummikalsum237@yahoo.co.id
}

\begin{abstract}
On December 23, 2018, a tsunami caused by the eruption of Mount Anak Krakatau in the Sunda Strait hit the coastal areas of Banten and Lampung. There were at least 426 people killed and 7,202 injured and 23 people missing due to this incident. One of the areas affected by this disaster is the Special Economic Zone (KEK) of Tanjung Lesung Tourism, which was officially opened in February 2015. With this incident, the Tourism sector in the area needs to be considered starting from the development and post-disaster plans. This research was conducted to be able to map out how the potential of new tourism due to disasters that can be used as a plan to develop tourist attractions in the region. This research was conducted qualitatively by involving various key informants as sources of data needed such as the head of the Local Tourism Office, coastal community leaders affected by the disaster, affected communities, hotel owners around the disaster area. From the results of these data and used as a source of information to be used as a result of research. The results of this study are how a new potential emerges utilizing the areas of the former disaster and mystery stories in the disaster which consist of 3A namely Attractions, Accessibility, and Amenity. In the element of tourist attraction that is owned or that has been planned by PT. Banten West Java Tourism (BWJ) has the potential to become one of the main tourist destination areas by establishing the development of the Dark Tourism area. Accessibility improvements to the access road are quite adequate to be used as access to tourist attractions, Amenitas in this element the addition of monumental features that remember the events of this disaster occurred.
\end{abstract}

Keywords: Dark Tourism; Disaster Tourism; Tanjung Lesung.

\begin{abstract}
Abstrak
Krakatau di Selat Sunda menghantam daerah pesisir Banten dan Lampung. Sedikitnya ada 426 orang tewas dan 7.202 terluka dan 23 orang hilang akibat peristiwa ini. Salah satu Kawasan yang terdampak dari bencana ini yaitu Kawasan Ekonomi Khusus (KEK) Pariwisata Tanjung Lesung yang di mana Kawasan ini diresmikan beroperasi pada Februari 2015. Dengan kejadian tersebut sektor Pariwisata pada Kawasan tersebut sangat butuh diperhatikan dimulai dari pengembangan dan rencana pasca bencana. Penelitian ini dilakukan untuk dapat memetakan bagaimana potensi Pariwisata baru akibat bencanan yang dapat dimanfaatkan sebagai rencana pengembangan daya tarik wisata di Kawasan ini. Penelitian ini dilakukan secara kualitatif dengan melibatkan berbagai informan - informan kunci sebagai sumber data yang diperlukan seperti kepala Dinas Pariwisata Setempat, tokoh masyarakat pesisir yang terkena bencana, masyarakat yang terkena bencana, pemilik pemilik hotel sekitaran bencana. Dari hasil data tersebut dan dijadikan sebuah sumber informasi untuk dijadikan suatu hasil penelitian. Hasil dari penelitian ini bagaimana suatu potensi - potensi baru muncul memanfaatkan area - area bekas bencana dan cerita cerita misteri pada bencana tersebut yang terdiri dari 3A yaitu Atraksi, Aksesibilitas, dan Amenitas. Pada elemen atraksi wisata yang dimiliki ataupun yang telah direncakan oleh PT. Banten West Java Tourism (BWJ) sangat berpotensi untuk dijadikan salah satu kawasan tujuan utama wisata dengan menetapkan pengembangan kawasan Dark Tourism. Aksesibilitas perbaikan jalan akses terbilang memadai untuk dijadikan akses menuju daya tarik wisata, Amenitas pada elemen ini penambahan fitur - fitur monumental yang mengenang peristiwa bencana ini terjadi.
\end{abstract}

Keywords: Dark Tourism; Wisata Bencana; Tanjung Lesung.

* Corresponding author 


\section{A. PENDAHULUAN}

Pada tanggal 22 Desember 2018, peristiwa tsunami yang disebabkan oleh letusan gunung Anak Krakatau di Selat Sunda menghantam daerah pesisir Banten dan Lampung, Indonesia (Prasetya et al., 2019; Rahmawati et al., 2020). Sedikitnya 426 orang tewas dan 7.202 terluka dan 23 orang hilang akibat peristiwa ini. Menurut Badan Meteorologi, Klimatologi, dan Geofisika (BMKG), tsunami disebabkan pasang tinggi dan longsor bawah laut karena letusan gunung tersebut. Sekitar 400 rumah di Pandeglang yang terletak di dekat pantai roboh atau rusak berat akibat tsunami. Selain itu, 9 hotel di Pandeglang dan 30 rumah di Lampung Selatan juga rusak berat. Jalan raya yang menghubungkan Serang dan Pandeglang terputus. Salah satu kawasan yang sangat terimbas dari bencana ini yaitu Kawasan Ekonomi Khusus (KEK) Pariwisata Tanjung Lesung (Gambar 1) yang di mana kawasan ini diresmikan beroperasi pada Februari 2015. KEK Tanjung Lesung memiliki luas area sekiatar 1500 hektare dengan potensi pariwisata, antara lain keindahan alam pantai, keragaman flora, dan fauna serta kekayaan budaya.

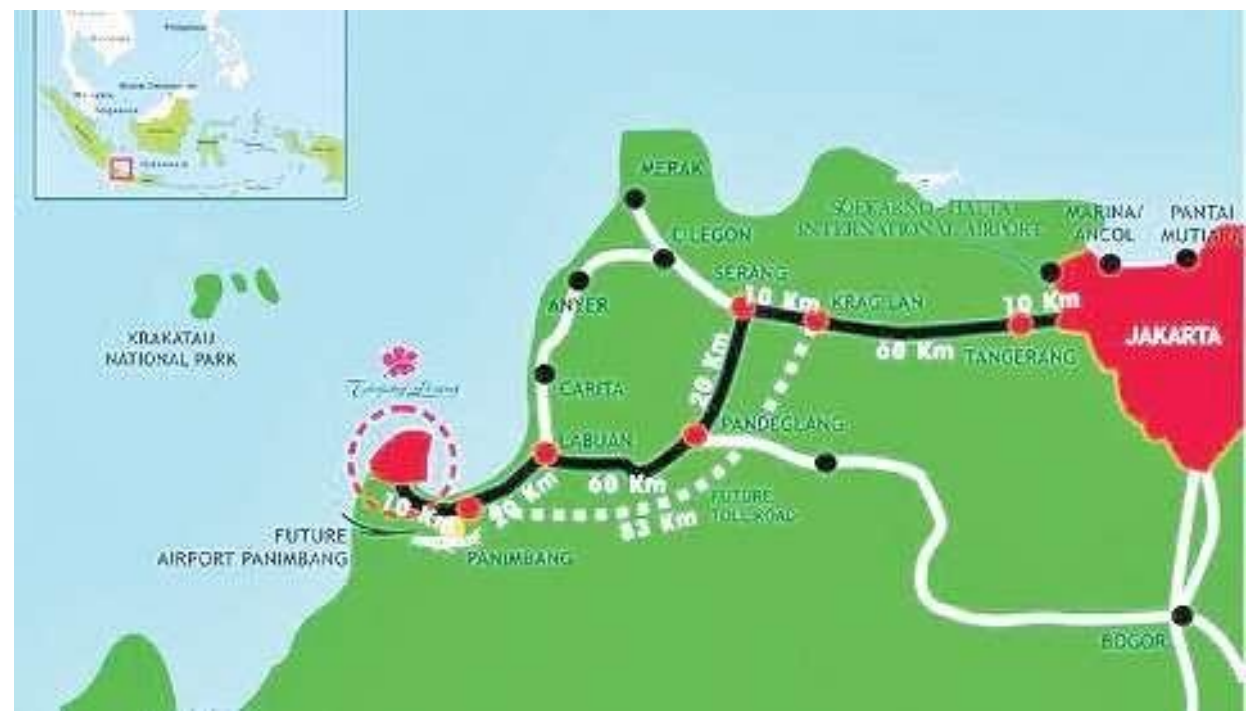

\section{Gambar 1 Kawasan KEK Tanjung Lesung}

Kawasan wisata KEK Tanjung Lesung yang dikelola PT Kawasan Industri Jawabebeka Tbk (KIJA) melalui anak perusahaannya, PT Banten West Jawa Tourism Development (BWJ). Pengembangan KEK Tanjung Lesung ini akan selesai pada Tahun 2022 dengan total Investasi mencapai Rp. 4.83 Triliun. Dengan sudah adanya Masterplan KEK Tanjung Lesung ini menjadi sebuah acuan dalam mengembangankan khususnya Pariwisata di kawasan ini. Akan tetapi dengan adanya suatu gangguan yang tidak dapat diprediksi (force majure) yaitu bencana alam, bencana yang terjadi akan sangat mempengaruhi beberapa elemen - elemen dalam pengembangan yaitu peta potensi daya tarik wisata yang ada. Menurut Novelli 2005 dalam konsep Alternative Tourism perkembangan pariwisata yang pesat membutuhkan inovasi dalam aktivitasnya karena beberapa wisatawan memiliki ketertarikan yang berbeda. Fenomena 'Dark Tourism' dalam beberapa tahun terakhir mungkin sampai batas waktu tertentu merupakan tren di kalangan akademisi (Hartmann, 2014; Stone, 2012) untuk menyususn bentuk- bentuk khusus pariwisata, atau pembagian jenis pariwisata sering disebut sebagai wisata minat khusus (Yankholmes \& McKercher, 2015). Dark Tourism Tourism memiliki banyak nilai, memalui pengembangan pariwisata, Dark Tourism bias menjadi pemahaman dan kesaradan akan bencana alam, yang bias 
membuat wisatawan 'terkejut'. Sehingga, orang dapat mengenali bencana alam yang menakjubkan dan kekejaman yang merupakan bencana buatan tangan manusia, dan juga meningkatkan kesadaran dan kemampuan untuk mencegah dan menagani bencana (Stone, 2011).

Beberapa contoh Penelitian daya tarik wisata 'Dark Tourism' di beberapa wilayah Indonesia yang terkena bencana yang terintegrasi dengan baik menjadi suatu rangkaiaan perjalanan wisata yang menarik. Muktaf (2017) meneliti wisata bencana pada Lava Tour di Gunung Merapi. Dalam penelitiannya wisata Lava Tour sangat diminati masyarakat karena mengandung unsur edukasi dan terdapat interaksi langsung antara pengunjung dan masyarakat sekitar yang terdampak bencana Gunung Merapi (Andajani, 2018; Muktaf, 2017). Penelitian lainnya masih dari Kawasan Gunung Merapi adalah mengenai Bungker Kaliadem (Muhamad, 2017). Kawasan wisata Bungker Kaliadem dibuat menjadi Kawasan wisata dengan tema ekologi serta dijadikan sebagai pengembangan tapak kawasan budaya vulkanik, dan interaksi masyarakat sekitar yang sangat tinggi. Beberapa dokumentasi mengenai Dark Tourisme di wilayah Gunung Merapi bisa dilihat pada Gambar 2.

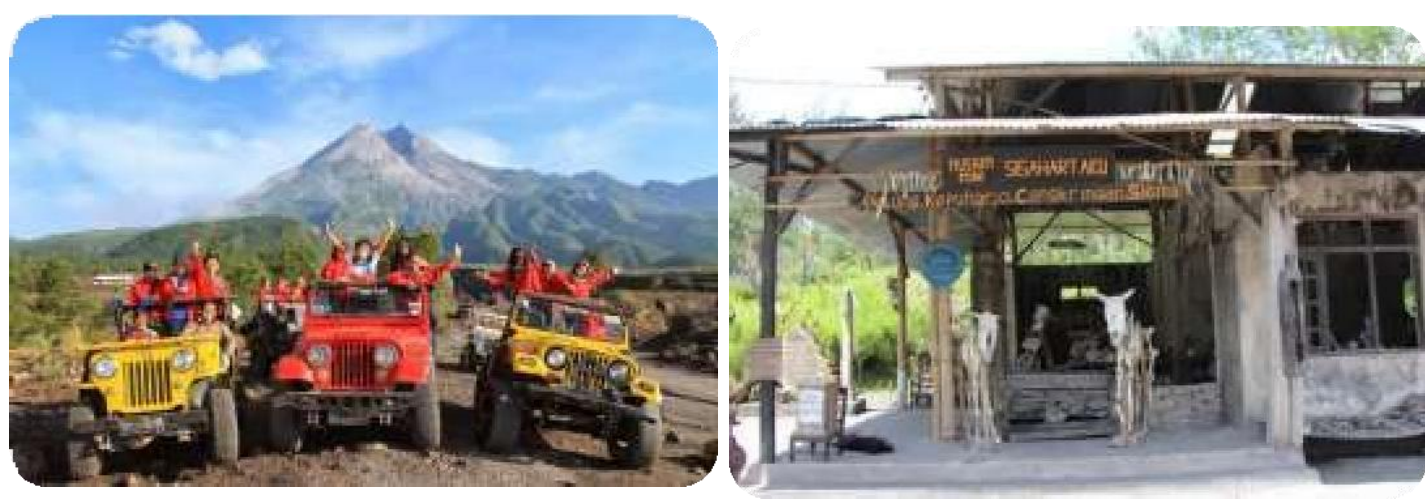

\section{Gambar 2 Kawasan Wisata 'Dark Tourism' Gunung Merapi}

Penelitian mengenai wisata bencana juga dilakukan pada wilayah Banda Aceh yang terkena Tsunami. Wulandari \& Safriana (2017) meneliti Kota Banda Aceh sebagai Kawasan wisata Bencana. Kawasan wisata ini menghadirkan cerita sejarah melalui replika objek dan kuburan yang dilengkapi tempat untuk berkontempelasi sebagai fasilitas pendukung (Wulandari \& Safriana, 2017). Masih Banda Aceh terdapat wisata museum Situs Kapal PLTD Apung Sebagai Objek Wisata Bencana Tsunami Kota Banda Aceh (Fahmi, 2018). Fahmi (2018) menemukan bahwa wisata bencana harus memenuhi kualitas layanan yang disajikan oleh fasilitas dan infrastruktur yang ada di wisata bencana. Namun mengingat sifat masyarakat yang mudah jenuh, diperlukan peningkatan dan penambahan infrastruktur baru agar masyarakat selalu dapat menyaksikan hal-hal baru pada PLTD Apung. PLTD Apung juga dijadikan pariwisata untuk tujuan mitigasi bencana Tsunami (Habibie \& Sjafie, 2017). Pada penelitian Rizkiyah, Liyushiana, \& Herman (2019) meneneliti pentingnya pemulihan ekonomi masyarakat yang terdampak oleh bencana tersebut melalui Pariwisata. Pada tulisan tersebut menghasilkan bahwa salah satu strategi pemulihan ekonomi melalui pariwisata tersebut yaitu penciptaan produk wisata unggulan berdasarkan lokalitas berupa wisata bencana (Rizkiyah et al., 2019).

Berdasarkan beberapa penelitian tersebut, daerah bencana merupakan kawasan yang hancur diterjang bencana yang besar dengan tingkat kerusakan yang cukup tinggi bisa dimanfaatkan untuk pariwisata dengan penambahan fasilitas monumental tambahan seperti museum, monument peringatan dan lainya dan kawasan ini berhasil memanfaatkan potensi dari dark tourism atau dark disaster. 
Tanjung Lesung meruoakan kawasan wisata yang terkena dampat Tsunami Selat sunda pada 22 Desember 2018 silam. Banyak wisatawan yang menjadi korban becana tersebut. Pasca bencana, tanjung lesung sepi dan beberapa fasilitas pariwisata seperti hotel, villa, resort, pondok, homestay, penginapan dan objek pariwisata lainnya rusak parah (Shali et al., 2019). Berdasarkan kondisi tersebut maka dari itu dibutuhkan suatu kajian identifikasi potensi pariwisata di kawasan KEK Tanjung Lesung pasca bencana agar dapat potensi - potensi pariwisata tersebut agar terintegrasi satu dengan lainnya guna memanfaatkan kondisi pasca bencana secara optimal, dan bermanfaat untuk masyarakat sekitar.

\section{B. METODE PENELITIAN}

Kawasan Ekonomi Khusus Tanjung Lesung sebagai Kawasan yang berdampak langsung oleh bencana ini sebagai objek penelitian melibatkan banyak informan - informan kunci seperti Kepala Dinas Pariwisata Daerah setempat, Tokoh - tokoh masyarkat sekitar, Pimpinan Hotel dan penginapan, dan masuarakat masyarakat sekitar. Metode penelitian yang akan digunakan dalam penelitian ini merupakan penelitian kualitatif dengan pendekatan deskriptif yang berusaha untuk menggambarkan secara aktual tentang satu keadaan, dalam hal ini tentang pengidentifikasian potensi wisata KEK pariwisata Tanjung Lesung pasca bencana sebagai dasar pengembangan daya tarik wisata. Penggunaan pendekatan kualitatif juga dipilih karena penelitian yang akan dilakukan cenderung menekankan pada kegiatan pengamatan atau observasi di lapangan. Data Primer hasil pengumpulan data tersebut dicatat dan didokumentasikan melalui hasil wawancara, observasi, dan checklist sebagai acuan dalam memetakan kondisi sumber daya pasca bencana yang ada kawasan wisata Tanjung Lesung. Pengambilan data sekunder dilakukan secara tidak langsung. Pengambilan data sekunder dilakukan yaitu dengan cara studi literatur dengan tujuan untuk mendapatkan intisari dari peneitian yang akan dilakukan dalam hal ini kawasan wisata Tanjung Lesung. Data yang dikumpulkan dapat menentukan nilai kemampuan mengidentifikasi area potensi wisata pasca benacana. Kegiatan pengumpulan data sekunder digunakan sebagai perkayaan data serta dapat menjadi alat pendukung sumber data dan informasi pada saat melakukan tahap analisis.

\section{HASIL DAN ANALISIS}

\section{Atraksi Wisata}

Atraksi wisata yang dimiliki ataupun yang telah direncakan oleh PT. Banten West Java Tourism (BWJ) sangat berpotensi untuk dijadikan salah satu kawasan tujuan utama wisata hal tersebut dikarenakan kawasan Tanjung Lesung ditetapkan sebagai kawasan 'kawasan ekonomi khusus pariwisata' oleh Undang Undang no 39 Tahun 2009 mengenai kawasan ekonomi khusus dan sudah terciptanya Rencana Induk Kawasan Ekonomi Khusus (KEK) Pariwisata Tanjung Lesung 2020 dari kawasan ini terdapat beberapa zona pembagian distrik:
a) Tanjung Lesung Highland
b) Tanjung Lesung Strait
c) Tanjung Lesung Bayside
d) Tanjung Lesung Point
e) Tanjung Lesung Harbour
f) Tanjung Lesung Heartland

Pada distrik - distrik tersebut memiliki tema - tema tertentu dalam pembangunannya hal ini sangat berpotensi dan baik untuk dijadikan acuan pembangunan Pariwisata pada kawasan KEK Tanjung Lesung agar pembangunan pariwisata pada kawasan ini terorganisir dalam pengembangan pembangunannya. 
Pada kawasan ini tema - tema pengembangan daya tarik wisata sangat bervariatif dan menarik untuk membuat para wisatawan tertarik untuk mengunjungi kawasan wisata ini.

\section{Aksesibilitas}

Secara umum jalan menuju ke Tanjung Lesung sangat membutuhkan pemeliharaan jalan maupun peningkatan jalan agar dapat menjadi mantap (baik jalan dengan permukaan beraspal (hotmix) maupun Betonisasi) guna memberi kenyamanan dan kemudahan bagi para wisatawan untuk mengakses Tanjung Lesung via jalur darat. Dalam hal ini sangat dibutuhkan kontribusi nyata dari pemerintah daerah untuk merevitalisasi kondisi jalan yang ada.

Berbicara lebih jauh seputar aksesibilitas menurut hasil observasilapangan, di dalam Kawasan Tanjung Lesung sendiri tersedia dua jenis jalan yakni jalan kelas tiga dan jalan setapak. Kondisi jalan kelas tiga yang ada di Kawasan ini sangat membutuhkan perbaikan dikarenakan meskipun jalan beraspal, jalan tersebut banyak yang berkerikil dan berlubang. Di sisi lain, kondisi jalan setapak di Kawasan ini khususnya jalan setapak jalur bersepeda di bibir pantai dalam kondisi berlubang akibat terpaan gelombang tsunami. Melihat hal ini, pihak pengelola perlu melakukan perbaikan atas kondisi jalan tersebut.

\section{Amenitas (sarana dan prasarana)}

Terdapat dua sumber daya listrik di Tanjung Lesung yakni aliran listrik dari PLN dengan kapasitas 200KWH bertegangan220 volt, dan Genset. Pasca Tsunami, kedua sumber listrik berjalan dengan distribusi yang baik sehingga mampu menopang segala kegiatan operasional yang sudah berjalan normal di Kawasan Tanjung Lesung. Kawasan Tanjung Lesung sejauh ini memiliki satu sumber air dengan jarak sumber air kurag dari 25 meter dengan debit air sebesar $50 \mathrm{~m}^{3}$. Meskipun terjadi bencana tsunami, sumber air di Kawasan Tanjung Lesung tidak terkontaminasi dengan limbah maupun material bawaan ombak gelombang tsunami sehingga kualitas, rasa dan bau air dalam kondisi normal (air jernih dan tawar tidak terasa rasa asin laut).

Kebersihan lingkungan di Kawasan Tanjung Lesung didukung oleh sistem pembuangan limbah yang memadai yakni adanya drainase WTP (Water Treatment) yang dibangun oleh pihak pengelola dan TPS yang diisediakan oleh pemda. Pasca tsunami, kondisi kawasan Tanjung Lesung sudah tertata rapih tidak ada material laut berupa sampah mauppun puing-puing bawaan gelombang tsunami yang berserakan di Kawasan Tanjung Lesung. Sistem komunikasi di Kawasan Tanjung Lesung pasca tsunami sudah berjalan dengan normal baik dari segi komunikasi melalui media intercom, penggunaan wi-fi, maupun kestabilan sinyal operator telpon selular sudah kembali normal.

Sarana umum berupa kantor pengelola, jalur evakuasi, dan shelter evakuasi tsunami tidak mengalami kerusakan yang berarti. Semua sarana tersebut dalam kondisi baik dan dapat digunakan untuk kepentingan umum. Namun, terkait shelter dan jalur evakuasi perlu mendapatkan perawatan agar mudah ditemukan oleh para wisatawan apabila terjadi bencana. Sebagai contoh, perlu di tambahkan lagi rambu penanda jalur evakuasi serta perlu dibangun suatu bangunan sebagai shelter evakuasi.

Sarana wisata di kawasan Tanjung Lesung dapat ditemukan dalam bentuk golf car, peralatan water sport (jet ski, banana boat, perahu, dan lain-lain), restoran dan akomodasi penginapan. Pasca tsunami, beberapa armada golf car dan peralatan water sport mengalami kerusakan.

\section{Potensi sumber daya pariwisata pasca bencana}

Dark Tourism merupakan salah satu jenis aktivitas di mana para wisatawan datang berkunjung ke lokasi yang memiliki sejarah peristiwa tragis. Berdasarkan observasi lapangan di kawasan Tanjung Lesung, terdapat beberapa potensi pariwisata yang dapat dikembangkan dan masuk ke dalam dimensi 
wisata berjenis Dark Tourism. Berikut adalah beberapa temuan lapangan yang dapat dikembangkan menadi wisata Dark Tourism berdasarkan dua dari delapan dimensi produk wisata

\section{Dark Exhibitions}

Berdasarkan hasil observasi lapangan, terdapat dua objek menarik yang dapat dikembangan menjadi daya tarik wisata berbasis produk Dark Exhibitions yakni beberapa jalur evakuasi, shelter evakuasi, dan lahan kosong. Adapun daya tarik tersebut sangat potensial untuk dikembangkan menjadi "Paket tour edukasi penanganan Bencana Tsunami". Pada beberapa jalur evakuasi, dapat dibuat lintasan baru yang letaknya di sekitar jalur evakuasi dan melintasi shelter evakuasi. Pembangunan lintasan baru tersebut pada penggunaannya digunakan sebagai lintasan untuk mengantarkan wisatawan menikmati tour di mana didalam tour tersebut wisatawan didampingi oleh pemandu yang menjelaskan tentang bagaimana peristiwa tsunami dapat terjadi dan bagaimana prosedur penyelamat diri ketika terjadi bencana tsunami. Terkait dengan Museum peringatan Tsunami, museum tersebut adalah suatu bangunan baru yang dapat dibangun di atas lahan kosong yang masih tersedia di kawasan Tanjung Lesung. Adapun pembangunan museum tersebut bertujuan untuk memberikan kesadaran akan bencana alam serta meningkatkan pemahaman untuk mencegah maupun menangani bencana. Di dalam museum tersebut dapat berisi beberapa benda maupun material yang terkena hempasan ombak tsunami, beberapa atraksi edukasi terkait proses terjadinya tsunami beserta simulasi penyelematan diri ketika terjadi tsunami.

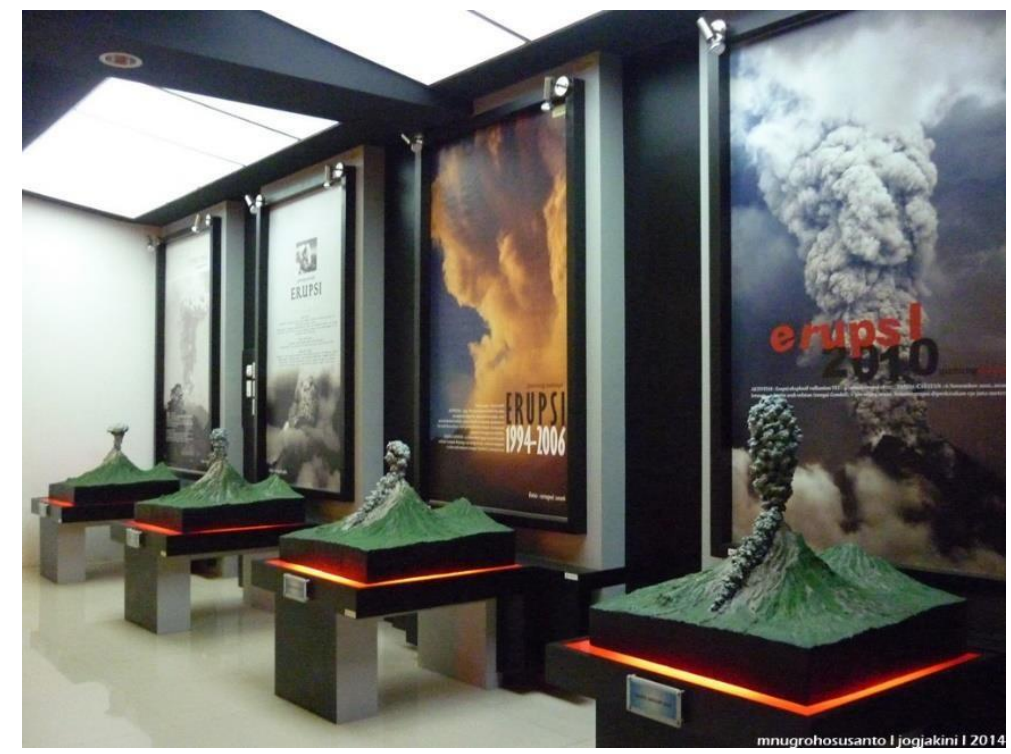

\section{Gambar 3 Contoh Ruangan Simulasi Bencana}

Gambar 3 merupakan diorama yang dapat dicontoh untuk dijadikan suatu daya tarik wisata yang dapat dikembangkan. Bagaimana akhirnya akan menjadi suatu daya tarik unggulan seperti pada Museum Tsunami di Aceh. 


\section{Dark of Disaster di Tanjung Lesung}

Terdapat dua titik terdampak tsunami yang memiliki potensi untuk pengembangan daya tarik berbasis produk Dark of Disaster yakni antara lain : Lalasa Beach Club dan Tanjung Lesung Beach Hotel. Lalasa Beach Club merupakan public beach yang dibuka oleh pihak pengelola bagi wisatawan yang tidak menginap di Tanjung Lesung Beach Hotel. Pada areal ini, beberapa objek mengalami kerusakaan akibat terpaan gelombang tsunami. Salah satu objek potensial yang dapat dikembangkan menjadi produk Dark Disaster adalah lalasa bridge. Lalasa bridge merupakan sebuah jembatan di mana sebelum terjadinya tsunami, jembatan ini menjadi salah satu icon daya tarik Tanjung Lesung dan biasa dijadikan sebagai spot bagi wisatawan untuk berfoto.

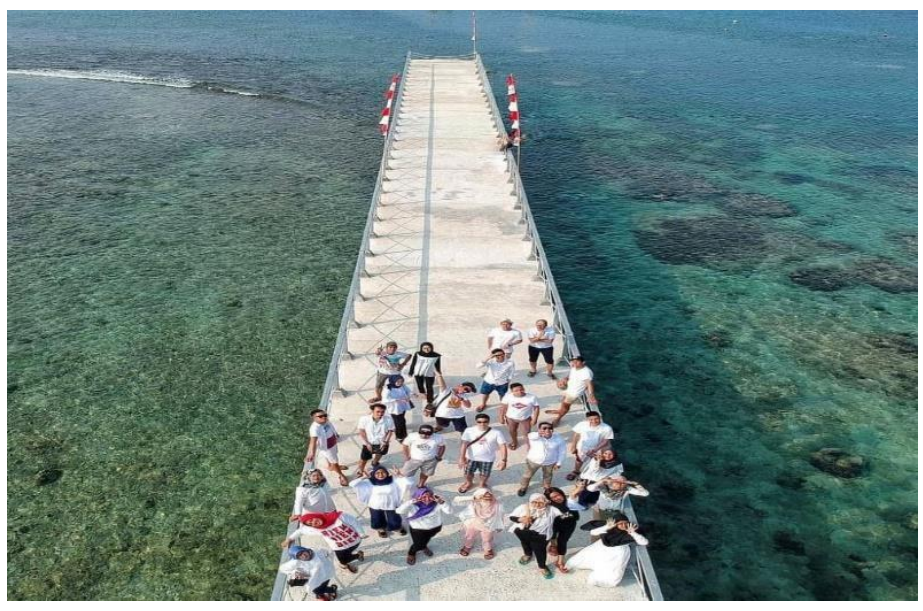

\section{Gambar 4 Lalasa Bridge}

Gambar 4 merupakan salah satu spot favorit para wisatawan untuk berswafoto namun pasca tsunami, jembatan ini mengalami kerusakan parah dan belum dilakukan tindakan perbaikan daripihak pengelola. Jembatan ini dapat dijadikan tempat berfoto bagi wisatawan yang ingin melihat bukti nyata dampak kerusakan yang ditimbulkan oleh gelombang tsunami. Selain lalasa bridge, di sekitar garis pantai dapat didirikan sebuah monument peringatan bencana tsunami serta dapat juga diadakan upacara keagamaan seperti pengajian. Di dalam pengajian tersebut dilakukan aktivitas ibadah memanjatkan doa bagi para korban maupun permohonan perlindungan dan berkah bagi Kawasan ini.

Tanjung Lesung Beach Hotel adalah salah satu akomodasi yang disediakan di Kawasan ini. Pada saat terjadi tsunami, anggota band seventeen sedang menghibur para tamu gathering PLN di pinggir pantai. Adapun panggung tempat band seventeen menghibur para tamu tak luput dari terpaan gelombang tsunami. Areal panggung ini dapat dijadikan daya tarik bagi para wisatawan yang ingin melihat penampakan areal stage pasca tsunami.

Gambar 5 merupakan areal panggung, di sekitar garis pantai dapat didirikan sebuah monument peringatan bencana tsunami serta dapat juga diadakan upacara keagamaan seperti pengajian. Di dalam pengajian tersebut dilakukan aktivitas ibadah memanjatkan doa bagi para korban maupun permohonan perlindungan dan berkah bagi Kawasan ini.

Terkait peta potensi Pariwisata secara terintegrasi, potensi wisata ini cukup sulit untuk dikembangkan mengingat fokus pihak pengelola saat ini adalah upaya proses pemulihan Kawasan terdampak tsunami. Tak hanya itu, pihak pengelola juga mengalami kendala dalam memulihkan trust masyarakat terkait keamanan berwisata di Tanjung Lesung pasca bencana tsunami. Selain kendala dari 
pihak pengelola, data peta potensi di atas menunjukan bahwa hanya ada dua dimensi dari delapan dimensi dark tourism yang dapat dikembangkan di Kawasan Tanjung Lesung. Dengan kata lain, potensi dark tourism yang ditemukan di Kawasan Tanjung Lesung hanya 25\% memenuhi syarat suatu potensi Pariwisata Dark Tourism dapat dipetakan secara terintegrasi.

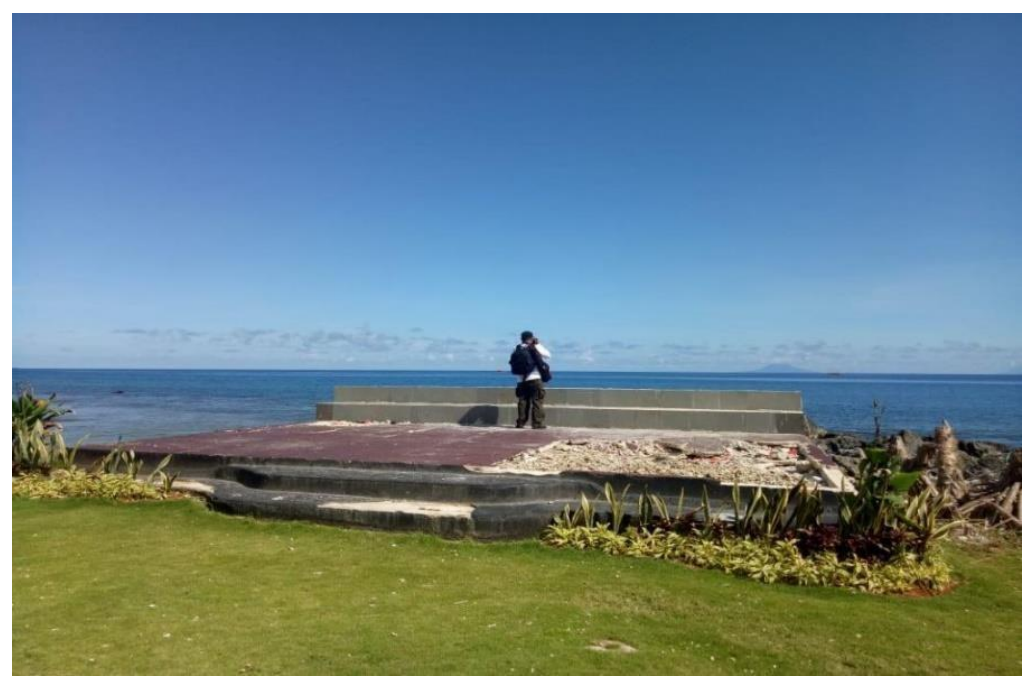

\section{Gambar 5 Lokasi Panggung Grup Band Seventeen}

\section{Sumber:https://www.brilio.net/jalan-jalan/kondisi-tanjung-lesung-kini}

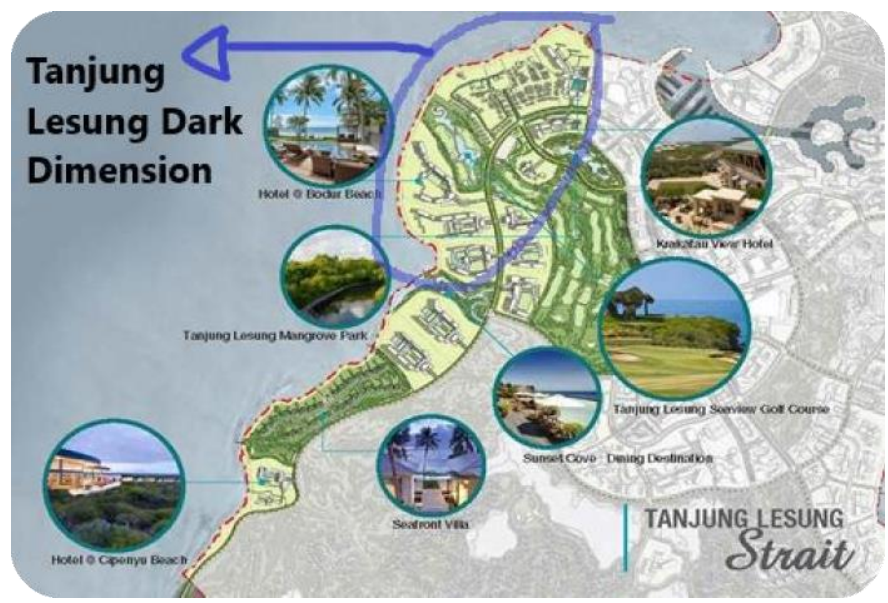

Figure 6 Zona Dark Tourism

\section{Sumber : PT. Banten West Java 2019 dan Olahan Peneliti}

Berdasarkan 6 diatas Zona Dark Tourism menunjukan bahwa dampak kawasan yang paling besar terkena terjangan Tsunami yaitu pada distrik Tanjung Lesung Strait di mana pada distrik ini mengusung tema Distrik yang terletak di sebelah barat kawasan Tanjung Lesung ini memiliki penawaran berbedayang ditawarkan oleh distrik lainnya, sebab distrik ini memiliki pemandangan berupa Gunung Krakatau, sun set, dan juga hutan mangrove yang tidak dimiliki oleh distriklain di kawasan Tanjung Lesung ini. Perlunya 
sebuah pengembangan tema dalam distrik ini berupa pemanfaatan lahan pasca Tsunami dijadikan Daya Tarik Wisata.

\section{SIMPULAN}

Berdasarkan dari hasil pemaparan serta pembahasan yang telah dilakukan sebelumnya, maka dapat disimpulkan beberapa hal sebagai berikut Potensi sumber daya pasca bencana dari berbagai aspek penilaian secara umum sudah baik dan dalam proses pemulihan. Meskiun demikian, kegiatan Pariwisata sudah mulai beroperasi dengan normal di Kawasan Tanjung Lesung. Terkait proses pemulihan, Kawasan Tanjung Lesung sangat membutuhkan bantuan nyata bantuan dari pemerintah daerah untuk perbaikan akses jalan serta pemulihan trust masyarakat dalam berwisata di Tanjung Lesung. Berdasarkan data hasil observasi, terkait pengembangan Dark Tourism di Kawasan Tanjung Lesung belum memungkinkan untuk dilaksanakan mengingat secara akses masih perlu perbaikan akses darat menuju Kawasan Tanjung Lesung serta perbaikan akses jalan aspal di dalam Kawasan Tanjung Lesung oleh pihak pengelola

Potensi pasca bencana yang dapat dikembangkan pada kawasan ini dapat dikembangkan pada Distrik Tanjung Lesung Strait karena kawasan ini merupakan kawasan yang terkena dampak paling besar mulai dari kerugian materil maupun moril pada kawasan ini telebih pada Tanjung Lesung Resort Beach Club. Pada Kawasan ini peta potensi terbagi menjadi dua yaitu peta potensi yang sudah dikembangkan oleh PT. Banten West Java dan Tim KEK Pariwisata Tanjung Lesung. Pertama yaitu peta potensi yang dihadirkan sesuai dengan Master Plan yang sudah dikaji dengan 6 Distrik pengembangan. Untuk peta kedua dapat diintegrasikan peta Dark Tourism pasca bencana yang berada pada Distrik Strait untuk dijadikan salah satu daya tarik dan pengembangan aktivitas maupun daya tarik.

Model pengembangan Aktivitas Wisata menitikberatkan pada bagaimana suatu distrik dan distrik lainnya terintegrasi dalam hal aktivitas yang dapat dilakukan, dapat juga dijadikan suatu model pengembangan aktivitas wisata berupa paket wisata 'Full Package' dan'Half Package' di mana pada paket tersebut terintegrasi beberapa aktivitas yang terdapat pada distrik - distrik yang tersedia termasuk zona Dark Tourism.

\section{REFERENSI}

Andajani, E. (2018). Dark tourism marketing through experience visit at East Java. 15th International Symposium on Management (INSYMA 2018).

Fahmi, U. (2018). Persepsi Masyarakat dan Wisatawan Terhadap Situs Kapal PLTD Apung Sebagai Objek Wisata Bencana Tsunami Kota Banda Aceh. Universitas Sumatera Utara.

Habibie, M. B., \& Sjafie, S. (2017). Mitigasi Bencana Tsunami Melalui Pariwisata (Studi Kasus di Situs Tsunami Kapal PLTD Apung Banda Aceh). Jurnal Ilmu Kebencanaan, 4(2).

Hartmann, R. (2014). Dark tourism, thanatourism, and dissonance in heritage tourism management: New directions in contemporary tourism research. Journal of Heritage Tourism, 9(2), 166-182.

Muhamad, M. (2017). Tapak Ekologi Kepariwisataan Alam Pada Zona Pemanfaatan Di Taman Nasional Gunung Merapi (TNGM)(Konsep Pengembangan Kepariwisataan Alam Tematik Tapak Kawasan Kalikuning-Kaliadem Sebagai Kawasan Budaya Vulkanik). Jurnal Kawistara, 7(3), 238-248.

Muktaf, Z. M. (2017). Wisata Bencana: Sebuah Studi Kasus Lava Tour Gunung Merapi. Jurnal Pariwisata, 4(2), 84-93.

Prasetya, G., Husrin, S., Kongko, W., Istiyanto, D., Hidayat, R., Asvaliantina, V., Kodijat, A., \& Fitriyana, F. (2019). Anak Krakatau Tsunami in Sunda Straits, Indonesia. Geophysical Research, 21.

Rahmawati, A., Khalifa, M. A., Indaryanto, F. R., Adrianto, L., Agus, S. B., \& Kurniawan, F. (2020). Seagrass existence after Sunda Strait tsunami 2018: Evidence in Tanjung Lesung region. E\&ES, 420(1), 12024. 
Rizkiyah, P., Liyushiana, L., \& Herman, H. (2019). Sinergitas Pentahelix Dalam Pemulihan Pariwisata Pasca Bencana Erupsi Gunung Api Sinabung Di Kabupaten Karo, Sumatera Utara. Jurnal IPTA, 7(2), 247-256. https://doi.org/10.24843/ipta.2019.v07.i02.p15

Shali, O., Tambunan, M. P., \& Tambunan, R. P. (2019). Membangun Ketahanan (Resiliensi) Bencana PadaKawasan Pariwisata (Studi Kasus: KabupatenPandeglang Pasca Tsunami Selat Sunda 2018). The 6th Annual Scientific Meeting on Disaster Research, 174-179.

Stone, P. R. (2011). Dark tourism and the cadaveric carnival: mediating life and death narratives at Gunther von Hagens' Body Worlds. Current Issues in Tourism, 14(7), 685-701.

Stone, P. R. (2012). Dark tourism and significant other death: Towards a model of mortality mediation. Annals of Tourism Research, 39(3), 1565-1587.

Wulandari, E., \& Safriana, D. (2017). Konsep Pengembangan Kota Banda Aceh sebagai Kota Wisata Tsunami. Jurnal Arsitektur ARCADE, 1(1), 1-7.

Yankholmes, A., \& McKercher, B. (2015). Rethinking slavery heritage tourism. Journal of Heritage Tourism, 10(3), 233-247. 